\title{
Behavior of Concrete/Cold Formed Steel Composite Beams: Experimental Development of a Novel Structural System
}

\author{
Nadim Wehbe ${ }^{1), *}$, Pouria Bahmani ${ }^{2)}$, and Alexander Wehbe ${ }^{3)}$
}

(Received January 5, 2013, Accepted February 12, 2013)

\begin{abstract}
The use of light-gauge steel framing in low-rise commercial and industrial building construction has experienced a significant increase in recent years. In such construction, the wall framing is an assembly of cold-formed steel (CFS) studs held between top and bottom CFS tracks. Current construction methods utilize heavy hot-rolled steel sections, such as steel angles or hollow structural section tubes, to transfer the load from the end seats of the floor joist and/or from the load-bearing wall studs of the stories above to the supporting load-bearing wall below. The use of hot rolled steel elements results in significant increase in construction cost and time. Such heavy steel elements would be unnecessary if the concrete slab thickening on top of the CFS wall can be made to act compositely with the CFS track. Composite action can be achieved by attaching stand-off screws to the track and encapsulating the screw shank in the deck concrete. A series of experimental studies were performed on full-scale test specimens representing concrete/CFS flexural elements under gravity loads. The studies were designed to investigate the structural performance of concrete/CFS simple beams and concrete/CFS continuous headers. The results indicate that concrete/CFS composite flexural elements are feasible and their structural behavior can be modeled with reasonable accuracy.
\end{abstract}

Keywords: composite concrete, concrete beam, cold-formed steel, light-gauge steel.

\section{Introduction}

The use of light-gauge steel (LGS) framing in low-rise commercial and industrial building construction has experienced a significant increase in recent years. In such construction, the wall framing is an assembly of cold-formed steel (CFS) studs held between top and bottom CFS tracks. The suspended floors are normally composite concrete/LGS decks spanning between load-bearing CFS walls. The composite floor system consists of a cast-in-place concrete floor supported by a corrugated steel deck. The decking is attached to the top chords of open-web steel joists by the means of stand-off screws. The stand-off screws serve as shear connectors that transfer shear stresses between the concrete slab and the top flanges of the open-web steel joists. The joist spacing in LGS construction can vary depending on the joist's load carrying capacity, the building's intended use, and the design requirements.

\footnotetext{
${ }^{1)}$ Department of Civil and Environmental Engineering, South Dakota State University, Brookings, SD 57007, USA.

*Corresponding Author;

E-mail: nadim.wehbe@sdstate.edu

${ }^{2)}$ Department of Civil and Environmental Engineering, Colorado State University, Fort Collins, CO 80523, USA.

${ }^{3)}$ Kiewit Engineering Co., Omaha, NE 68131, USA.

Copyright $($ The Author(s) 2013. This article is published with open access at Springerlink.com
}

Current construction methods utilize heavy hot-rolled steel sections, such as steel angles or hollow structural section (HSS) tubes, to transfer the load from the end seats of the floor joist and/or from the load-bearing wall studs of the stories above to the supporting load-bearing wall below. The steel sections are welded to the top of the CFS load-bearing wall and function either as load distribution members (LDM) over wall studs or as headers spanning wall openings. Figure 1 shows LGS framing with an HSS tube LDM and header at the top of the CFS wall. The use of hot rolled steel elements results in significant increase in construction cost and time. Such heavy steel elements would be unnecessary if the concrete thickening on top of the CFS wall can be made to act compositely with the CFS track. The resulting concrete/CFS composite beam would be a reinforced concrete beam where the CFS track serves as the tension reinforcement. Figure 2 shows a schematic of the proposed composite beam. The continuity at the interface between the CFS track and the concrete thickening would be provided by stand-off screws drilled into the CFS track prior to casting the slab's concrete. Figure 3 shows a $2 \frac{1}{2}$ in. long by $5 / 16$ in. diameter stand-off screw commonly used in composite deck construction and which could also be used as a shear connector in concrete/CFS composite beams.

Since concrete/CFS composite beams have not been considered before by the engineering community as viable structural elements, current building codes do not provide provisions for the design and construction of such beams. Therefore, research studies were needed to assess the feasibility of developing this novel structural system. In response 


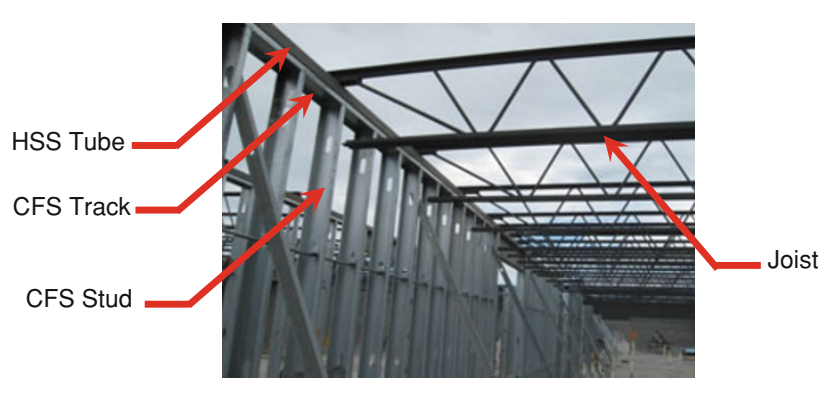

Fig. 1 Light-gauge steel framing.

to this need, a series of experimental studies were performed on full-scale test specimens representing concrete/CFS flexural elements under gravity loads. The studies were designed to investigate the structural performance of concrete/CFS simple beams and concrete/CFS continuous headers. This paper presents results from two experimental studies and discusses the basic behavior of concrete/CFS composite flexural elements.

\section{Concrete/CFS Composite Simple Beams}

Before concrete/CFS composite headers and LDMs could be investigated, the feasibility of using $2 \frac{1}{2}$ in. $\times 5 / 16$ in. stand-off screws for providing composite action had to be examined. Two groups of concrete/CFS composite simple beam test specimens, referred to as Group 1 and Group 2, were built to represent two different stand-off screw configurations. Three identical specimens of each configuration were constructed to verify repeatability of test results. The two cross sectional details of the test specimens are shown in Fig. 4. Each beam specimen was $9.75 \mathrm{ft}$. long and consisted of a $6 \mathrm{in}$. wide by $8 \mathrm{in}$. deep concrete section on top of a CFS track. The concrete section represented the slab thickening on top of a CFS track of a stud wall. The track was a C-shape section with 6 in. deep web and 2 in. wide flanges. The track thickness was 14-gauge (0.068 in.). According to the Steel Stud Manufacturers Association's (2012) (SSMA) cross section designation, the track thickness used in this study corresponds to CFS Sect. 600T200-68. When composite action is provided, the track acts as the tension reinforcement in the composite beam section. For a concrete strength of 3,000 psi and steel yield stress of $50 \mathrm{ksi}$, the maximum and minimum tension steel ratios in beams allowed by the ACI code (American Concrete Institute 2011) would be 0.0220 and 0.004 , respectively. Considering the given track cross sectional areas and an effective tension reinforcement depth $d$, measured to the centroid of the track, of $8.43 \mathrm{in}$., the tension steel ratio of the beam specimens would be 0.0141 . This steel ratio is well within the ACI allowable limits. Stand-off screw connectors were used to provide composite action between the CFS track and the concrete. The stand-off screws were placed in one row for the specimens in Group 1 and in two rows for the specimens in Group 2. In both groups, the center-to-center screw spacing along the beam's longitudinal axis was 6 in. It should be noted that no shear reinforcement was placed in the concrete. The test specimens were designated as 1-GA14-X and 2-GA14-X for specimens in Group 1 and Group 2, respectively, where GA14 denotes the track thickness of 14 gauge and $\mathrm{X}$ is the specimen number $(1,2$, or 3$)$ within the group.

\subsection{Material Properties}

The specified concrete compressive strength and the CFS track yield stress were 3,000 psi and $47 \mathrm{ksi}$, respectively. On the day of testing, the measured concrete compressive strength values varied between 3,520 and 4,260 psi. Coupon testing revealed that the yield stress of the CFS track was $45 \mathrm{ksi}$. The stand-off screws specified yield stress was $150 \mathrm{ksi}$, but the specified value was not verified experimentally. Based on the measured material properties and assuming full composite action, the nominal shear and flexural strengths were computed. The nominal shear strength of the concrete section was based on the ACI simplified shear stress of $2 \sqrt{f_{c}^{\prime}(p s i)}$ and the concrete section depth of 8.00 in. rather than the effective depth of $8.43 \mathrm{in}$. The measured concrete compressive strength results and the corresponding nominal shear and flexural strengths are reported in Table 1.

\subsection{Instrumentation and Test Setup}

The beam specimen was simply supported at a span of $9 \mathrm{ft}$. Two equal point loads were applied at the one-third points by means of a 22-kip hydraulic actuator and a steel spreader beam. The loading was applied in a displacement-

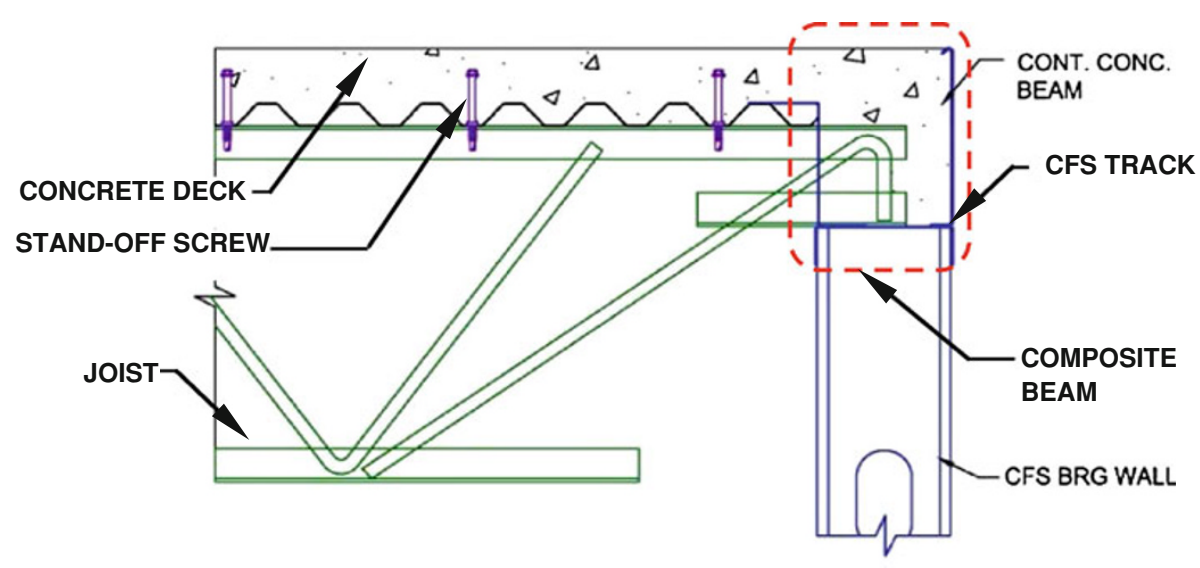

Fig. 2 Proposed composite beam. 


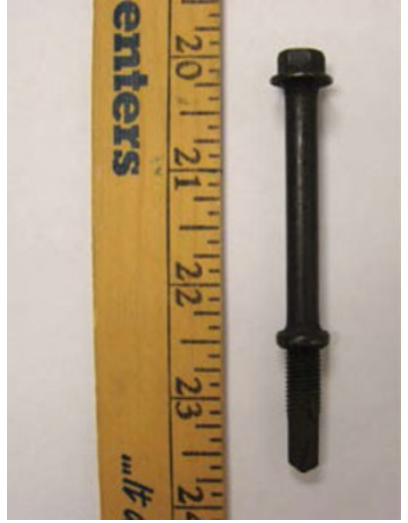

Fig. 3 Stand-off screw.

controlled mode until failure. Figure 5 shows the test setup. Strain in the track was measured using surface mounted strain gauges. The gauges were attached to the track at several locations along all three spans. Strain in the concrete was measured using embedded strain gages placed at $1.5 \mathrm{in}$. from the top of the section. The mid-span deflection under the applied load was measured by means of a pair of linear variable differential transducers (LVDT). The slip of the concrete relative to the track was measured at both ends of the specimen by means of LVDTs. More details on the instrumentation are provided by Wehbe (2009).

\subsection{Experimental Results and Discussion}

Overall, the specimens exhibited the same general cracking patterns beginning with initial cracking in the form of pure flexural cracks in the middle span followed by flexuralshear cracks just outside of the middle span. In general, the cracks initiated at locations of stand-off screws. The measured load-deflection relationships are shown in Fig. 6. The observed failure modes were either flexural in the constant moment region or flexural-shear in the proximity of the applied point load at one-third the span. The observed failure modes are shown in Fig. 7. All specimens experienced yielding in the flanges of the track. The yielding extended to the web except for specimen 1-14GA-1. Table 2 shows selected measured results for the tested specimens. The reported end slip in Table 2 represents the average of the relative slip between the concrete and the CFS track at both ends.

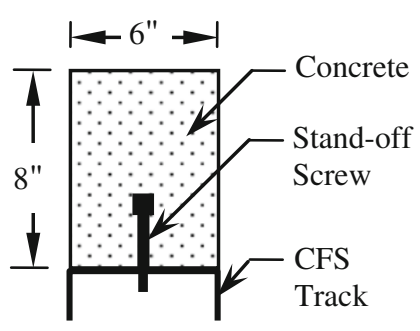

Group 1

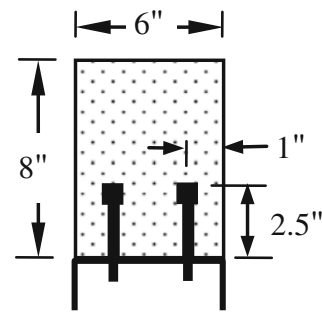

Group 2
Fig. 4 Cross sectional details of the beam test specimens.

When the stand-off screw quantity was increased from 1 screw at 6 in. to 2 screws at 6 in., the average strength increased by $53.8 \%$, the average effective stiffness, taken at an applied load of $6 \mathrm{kips}$, increased by $81.8 \%$, and the average measured slip for Group 1 specimens was more than six times that of Group 2 specimens. This indicates substantial improvement in composite action when the stand-off screw quantity is increased from 1 screw at 6 in. to 2 screws at 6 in. In order to determine the effectiveness of the standoff screws for providing composite action, theoretical load-deflection curves were derived from moment-curvature relationships of the respective sections. The theoretical moment-curvature relationships were developed using the computer software XTRACT V2.6.2 (Imbsen Software Systems 2000) and assuming fully composite sections. The software calculates the moment-curvature relationship based compatibility of strain and equilibrium of the internal forces considering the cross sectional composition (shape and materials) and the material properties of the constituent concrete and steel. Figure 8 shows theoretical and measured load-deflection relationships for the beam specimens in Groups 1 and 2. Also shown are some code-prescribed deflection limits (International Code Council (ICC) 2012) in terms of the span length, L. The results indicate that when the stand-off screw density was 1 screw at 6 in. (Fig. 8a), significant slippage took place and the specimen failed at approximately $33 \%$ lower than its theoretical flexural strength. However, for a stand-off screw density of 2 screws at 6 in. (Group 2), slippage was insignificant, the flexural strength was attained, and the theoretical and measured load-deflection relationships were in excellent agreement (Fig. 8b). Therefore, using 2 screws at 6 in. would be adequate for providing nearly full composite action.

Table 1 Nominal shear and flexural strengths for the beam specimens.

\begin{tabular}{c|c|c|c}
\hline Specimen ID & Measured concrete strength (ksi) & Nominal shear strength (kips) & Nominal flexural strength (kip-in) \\
\hline \hline $1-14 \mathrm{GA}-1$ & 3.52 & 5.70 & 214.9 \\
\hline $1-14 \mathrm{GA}-2$ & 3.52 & 5.70 & 214.9 \\
\hline $1-14 \mathrm{GA}-3$ & 4.26 & 6.27 & 218.2 \\
\hline $2-14 \mathrm{GA}-1$ & 4.15 & 6.18 & 217.6 \\
\hline $2-14 \mathrm{GA}-2$ & 4.15 & 6.18 & 217.6 \\
\hline $2-14 \mathrm{GA}-3$ & 4.22 & 6.23 & 217.9 \\
\hline
\end{tabular}




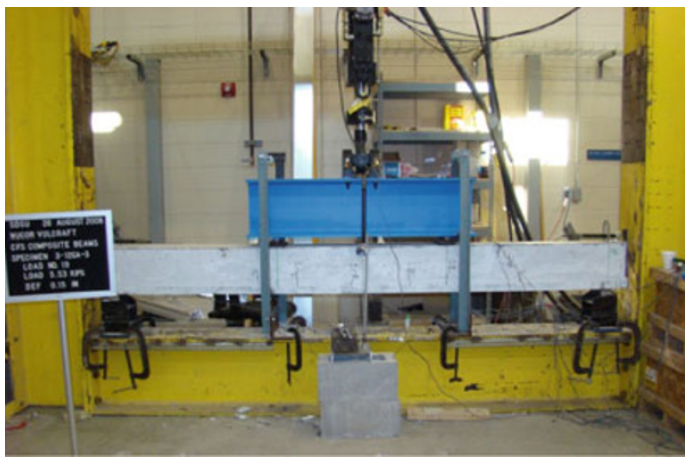

(a) Specimen Setup

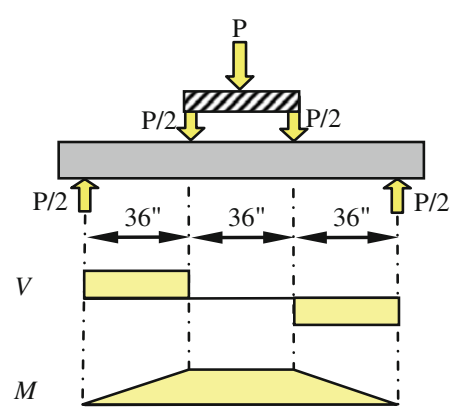

(b) Schematic of the Test Setup

Fig. 5 Test setup for the beam specimens.

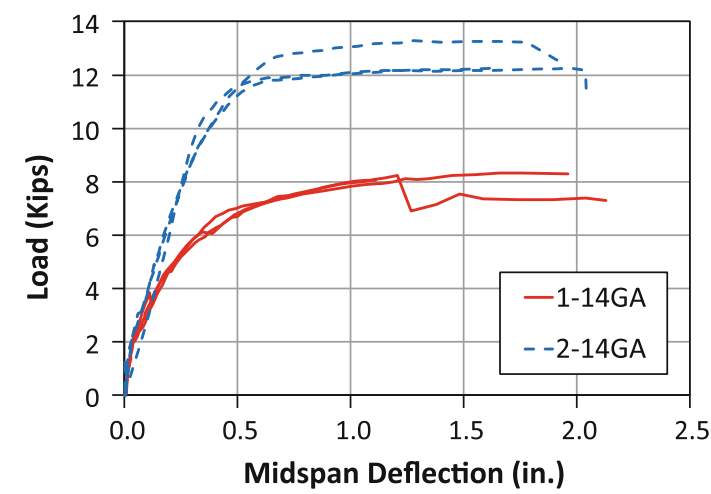

Fig. 6 Experimental load-deflection relationships for the beam specimens.

The degree of composite action in a composite section is dependent upon the ability of the section to transfer in-plane shear stresses at the interface of the two materials. The theoretical force carried by a stand-off screw was determined using the shear flow, $q$, of elastic beams:

$$
q=\frac{V Q}{I}
$$

where $V$ is the shear force, $Q$ is the static moment of the area above or below the horizontal shear plane, and $I$ is the transformed cracked moment of inertia. The computed shear force carried by a screw was found to be equal to 0.0645 kips per 1 kip of the applied shear force, $V$. The force in the screw was also determined experimentally by measuring the strain in the CFS track at two predetermined reference sections in each shear span. Knowing the strain at a reference section, the corresponding tension force in the track was computed at that location. The force per stand-off screw was then determined by dividing the change in the tensile force by the number of standoff screws between the two reference sections. Plots of the theoretical and experimental force per stand-off screw versus the applied total load are presented in Fig. 9. The results indicate a very good agreement between the theoretical and experimental values until the point of first measured relative slip between the concrete and the CFS track.
In this study, the force carried by a stand-off screw was compared to the nominal bearing capacity of the screw in the CFS track. The 2007 Edition of the American Iron and Steel Institute (2007) (AISI) provides provisions for the bearing strength of bolted connections. Separate design equations are presented for the case when hole deformation is a design consideration and the case when hole deformation is not a design consideration. When hole deformation is a design consideration, a maximum $1 / 4$ in. hole deformation is allowed. The AISI provides the following equation for determining the nominal bearing strength for the case of limited hole deformation:

$$
P_{n}=(4.64 \alpha t+1.53) d t F_{u}
$$

where $\alpha$ is a coefficient for conversion of units ( $=1$ for US customary units with $t$ in inches), $d$ is the nominal bolt diameter, $t$ is the uncoated steel sheet thickness, and $F_{u}$ is the tensile strength of the steel sheet. When hole deformation is not a design consideration, the nominal bearing strength is determined using the following equation:

$$
P_{n}=C m_{f} d t F_{u}
$$

where $C$ is a bearing factor obtained from AISI Table E3.3.1-1 and $m_{f}$ is a modification factor for the type of bearing connection in accordance with AISI Table E3.3.1-2. Since only the yield strength, $F_{y}$, of the CFS track was measured experimentally, $F_{u}$ was assumed to be equal to $1.25 F_{y}$ when calculating $P_{n}$. For the CFS track and stand-off screw used in this study, the nominal bearing strength would be $2.21 \mathrm{kips}$ when hole deformation is limited and 2.55 kips when hole deformation is not a design consideration. Based on the experimental results shown in Fig. 9, the total applied load corresponding to stand-off screw forces of 2.21 and 2.55 kips would be approximately 12.0 kips. It should be noted that the theoretical flexural strength of the test specimens is attained at a total applied load of approximately 12 kips (corresponding to a moment of $216 \mathrm{kip}$-in). At the strength limit state, the hole deformation would enhance the system's ductility by increasing the beam deflection without significantly affecting its strength. Therefore, Eq. (3) should be adequate for selecting the size and spacing of the stand-off screws. 


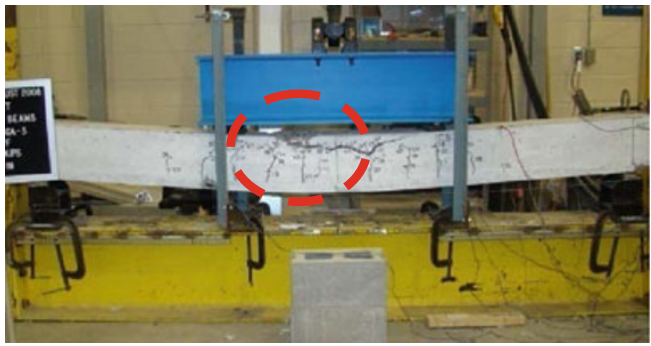

(a) Flexural Failure

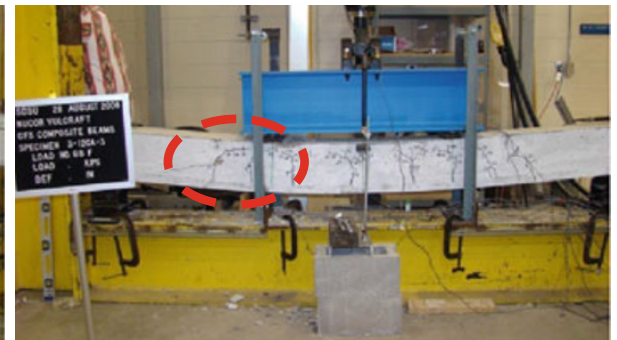

(b) Flexural-Shear Failure

Fig. 7 Observed failure modes for the beam specimens.

Table 2 Summary of experimental results for the beam specimens.

\begin{tabular}{c|c|c|c}
\hline Specimen ID & $\begin{array}{c}\text { Measured maximum total load } \\
\text { (kips) }\end{array}$ & Average total end Slip (in) & Failure mode \\
\hline \hline $1-14 \mathrm{GA}-1$ & 8.33 & 0.26 & Flexural-shear \\
\hline $1-14 \mathrm{GA}-2$ & 8.33 & 0.22 & Flexural-shear \\
\hline $1-14 \mathrm{GA}-3$ & 8.05 & 0.17 & Flexural-shear \\
\hline $2-14 \mathrm{GA}-1$ & 13.29 & 0.04 & Flexural \\
\hline $2-14 \mathrm{GA}-2$ & 12.25 & 0.03 & Flexural-shear \\
\hline $2-14 \mathrm{GA}-3$ & 12.25 & 0.03 & Flexural \\
\hline
\end{tabular}

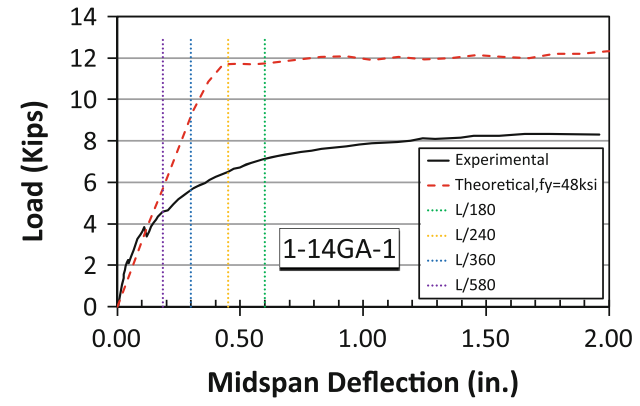

(a) Group 1 specimen

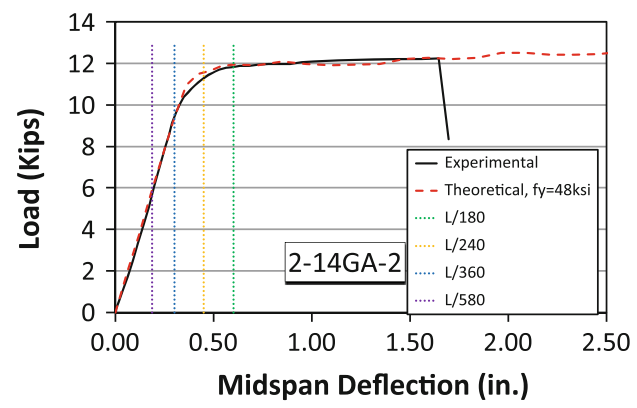

(b) Group 2 specimen

Fig. 8 Theoretical and experimental load-deflection relationships for two beam specimens.

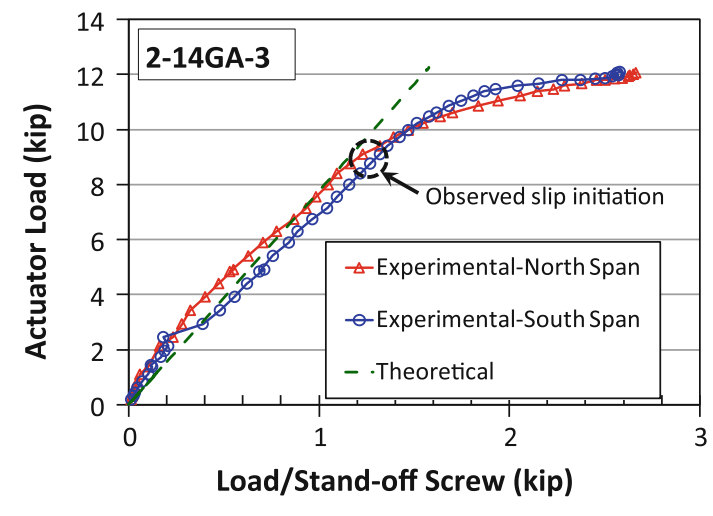

Fig. 9 Theoretical and experimental load carried by a standoff screw.

For deflection computations, the ACI code (American Concrete Institute 2011) permits the use of an effective moment of inertia, $I_{e}$, that can be determined using the following empirical equation:

$$
I_{e}=\left(\frac{M_{c r}}{M_{a}}\right)^{3} I_{g}+\left[1-\left(\frac{M_{c r}}{M_{a}}\right)^{3}\right] I_{c r}
$$

where $M_{c r}$ is the cracking moment, $M_{a}$ is the maximum service load bending moment in the beam, $I_{g}$ is the gross moment of inertia based on the concrete section, and $I_{c r}$ is the cracked moment of inertia. The cracking moment corresponds to the modulus of rupture as determined from Eq. (5):

$$
f_{r}=7.5 \sqrt{f_{c}^{\prime}(p s i)}
$$

Equation (4) was derived for conventional reinforced concrete sections where the location of the tensile reinforcement is closer to the neutral axis than the extreme concrete tensile fiber is. Since this is not the case for the composite concrete/CFS section, the applicability of Eq. (4) to the beams in this study needed to be verified against the 
experimentally measured $I_{e}$. The experimental loaddeflection results were used to back calculate values for $I_{e}$ at different applied loads using the elastic beam loaddeflection relationship. The elastic modulus of the composite section was assumed to be equal to that of the concrete, $E_{c}$, as given by the following ACI (2011) expression:

$$
E_{c}=57000 \sqrt{f_{c}^{\prime}(p s i)}
$$

The back calculated and the code effective moment of inertia values for one of the test specimens are plotted against the applied moment $\left(M_{a}\right)$ in Fig. 10. Also shown are the theoretical $M_{c r}$ and the best fit line for the experimental $I_{e}$. The ACI based $I_{e}$ was approximately 220 in $^{4}$ (Imbsen Software Systems 2000). Up to approximately 3.2 times the cracking moment, the ACI expression results in lower effective moment of inertia than the experimentally based value and, therefore, higher estimates of the deflection. For $M_{a}$ above 3.2 $M_{c r}$, the ACI based $I_{e}$ becomes higher than the experimental $I_{e}$. At an applied moment of $180 \mathrm{kip}-\mathrm{ft}$, the ACI based $I_{e}$ is 1.42 times the experimental $I_{e}$. Hence, further investigation is needed to derive an appropriate expression for $I_{e}$ for concrete/CFS composite beams.

\section{Concrete/CFS Composite Continuous Headers}

A total of four CFS wall with composite concrete beam test specimens were fabricated and tested until failure. The main purpose for the tests was to evaluate the structural performance of composite concrete/CFS beams when used as load-bearing headers over wall openings.

Each test specimen represented a $12 \mathrm{ft}$. long segment of a CFS wall frame with a $6 \mathrm{ft}$. long header spanning over a wall opening that was centered at the wall's mid-length. The wall framing consisted of the following standard CFS sections: 600S162-68 (14-gauge) studs, 600T200-97 (12-gauge) top track, and 600T125-43 (18-gauge) bottom track. One 6 in. $\times 3$ in. $\times 0.375$ in. HSS king stud was used to support each end of the composite header. The wall frame was only $20 \mathrm{in}$. high to avoid premature buckling of the wall studs during load testing.

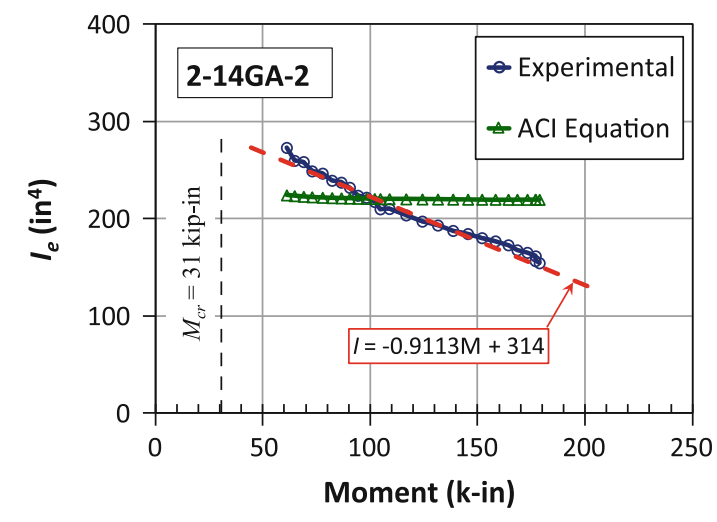

Fig. 10 Code and experimental effective moment of inertia.
A concrete beam having a 6 in. wide by 8 in. deep cross section and representing the concrete floor thickening above the wall was cast on top of the entire CFS wall specimen. The concrete beam was built to act compositely with the frame's top CFS track over the wall opening only. Composite action was provided by means of $2 \frac{1}{2}$ in. $\times 5 / 16$ in. stand-off screws placed in two rows and spaced at 6 in. on center over the opening length. The selection of the stand-off screw size and arrangement was based on the results of the composite beams study described in the previous section. The concrete in the beam was reinforced with two \#4 longitudinal top steel bars that were placed 1 in. below the top of the beam. The top reinforcement was needed to provide flexural strength in the negative moment regions over the king studs. Shear reinforcement was provided in the form of a single layer of $3 \times 3-\mathrm{W} 2.1 \times \mathrm{W} 2.1$ or $4 \times 4-\mathrm{W} 2.1 \times$ W2. 1 mesh. Although the $4 \times 4-\mathrm{W} 2.1 \times \mathrm{W} 2.1$ mesh was theoretically adequate for the shear reinforcement, the higher shear reinforcement amount provided by the $3 \times 3-\mathrm{W} 2.1 \times$ W2.1 mesh was also used to compare the performance of the two shear reinforcements in the event of development of premature wide shear cracks in the concrete. Figure 11 presents the cross sections of the Concrete/CFS composite test specimens. Based on the shear reinforcement, the four specimens were divided into two groups with two specimens in each group. In each group, one specimen was subjected to a single point load, while the other was subjected to two point loads. The two loading schemes were selected to represent actual loading conditions in the field where either one or two joists could potentially be carried by the header. The specimens were labeled using a Roman numeral followed by a single-digit number to reflect the shear reinforcement, and loading pattern. The Roman numerals "I" and "II" indicate shear reinforcement consisting of $3 \times 3-\mathrm{W} 2.1 \times \mathrm{W} 2.1$ and $4 \times 4-\mathrm{W} 2.1 \times \mathrm{W} 2.1$ wire-mesh, respectively. The numbers " 1 " and " 2 " represent singlepoint and two-point loading, respectively.

\subsection{Material Properties}

On the day of testing, the measured average concrete compressive strength values were $4.25 \mathrm{ksi}$ for specimen I-1, $5.32 \mathrm{ksi}$ for specimens I-2 and II-1, and $5.16 \mathrm{ksi}$ for specimen II-2. The specified yield stresses for the CFS top track

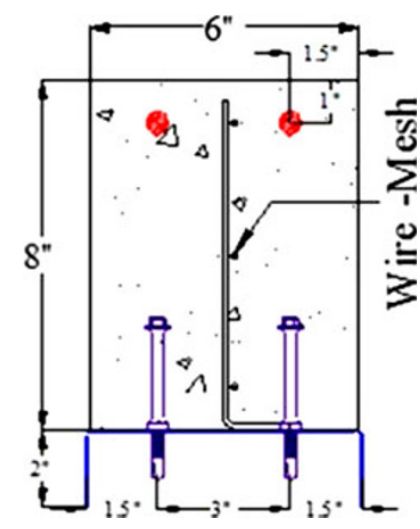

Fig. 11 Cross section of the composite header. 
and the steel bars were 50 and $60 \mathrm{ksi}$, respectively; however, the specified values were not verified experimentally.

\subsection{Instrumentation and Test Setup}

The specimens were instrumented with an array of strain gauges, load cells, and displacement transducers. Additional information on the instrumentation can be found elsewhere (Bahmani 2010). The applied loading was static and consisted of either single-point or two-point loading. Figure 12 presents the two loading schemes. Each specimen was held down to the laboratory's strong floor by the means of two tie-down prestressing bars placed at 12 in. from each end of the specimen. The tie-downs represented point loads on the wall away from the wall opening. The force in the tie-downs increased with an increase in the applied load. The loading was applied by a 146-kip hydraulic actuator and was monotonic under displacement-controlled loading.

\subsection{Experimental Results and Discussion}

The total applied load versus mid-span deflection for the test specimens are shown in Fig. 13. Specimens that were subjected the same loading scheme exhibited relatively similar cracking patterns. The initial cracks in the form of pure flexural cracks occurred at locations of maximum bending moment. For Specimens I-1 and II-1 (single-point load), the first positive moment crack occurred at mid-span at an applied load of 5.96 and 6.40 kips, respectively, while the first negative moment crack occurred above one of the king studs at an applied load of 15.9 and $18.5 \mathrm{kips}$, respectively. For Specimens I-2 and II-2 (two-point load), the first positive moment crack occurred within approximately 2 in. from mid-span at an applied load of 7.62 and 7.79 kips, respectively, while the first negative moment crack occurred above one of the king studs at an applied load of 24.1 and $26.0 \mathrm{kips}$, respectively. As the load was increased, additional flexural and flexural-shear cracks developed until failure. Except for Specimen II-2, failure of the specimen occurred in flexure by crushing of the compression concrete under a point load, followed by an excessive inclined shear crack that extended from the loading point to the bottom of the concrete section. For specimen II-2, flexural and shear failures occurred simultaneously. Figure 14 shows a flexural failure and the observed cracking patterns.

The average load-carrying capacities for the single-point and the two-point load specimens were 35 and 45 kips $(22.5$ kips/point load), respectively. The load-deflection curves for the two-point load specimens were very identical. However, the load-deflection curves for the single-point load specimens indicate that Specimen I-1 was stiffer than Specimen II-1 up to the formation of first negative moment crack. This anomaly was the result of the test procedure; the testing of Specimen I-1 was interrupted at a load of 14.7 kips due to malfunctioning of the data acquisition system. The specimen was unloaded then the test was restarted from a zero load. Since the CFS studs and tracks are connected by means of self-tapping screws, the first loading excursion allowed for any slippage at the screwed CFS frame joints to take place. Thus, the second loading excursion did not include the softening effect resulting from slippage of the jointing screws.

Building codes specify a deflection limit of $L / 240$ under the combined service dead and live loads, where $L$ is the span length (International Code Council (ICC) 2012). For the $6 \mathrm{ft}$. header considered in this study, the deflection limit would be $0.3 \mathrm{in}$. The measured average total load at $0.3 \mathrm{in}$. was 22.3 and $27.6 \mathrm{kips}$ for the single-point and two-point loading, respectively. These load values correspond to the total service load limit that can be applied without exceeding the deflection limit of $L / 240$.

The theoretical flexural and shear strengths of the concrete/CFS headers were computed in order to determine the ultimate load carrying capacity of the headers under singleand two-point loads. Under negative bending, the flexural reinforcement consisted of two \#4 top bars. Under positive bending, the flexural reinforcement was assumed to consist of the CFS track. Flexural capacities were determined from moment-curvature relationships for a header section under positive and negative bending moments. The
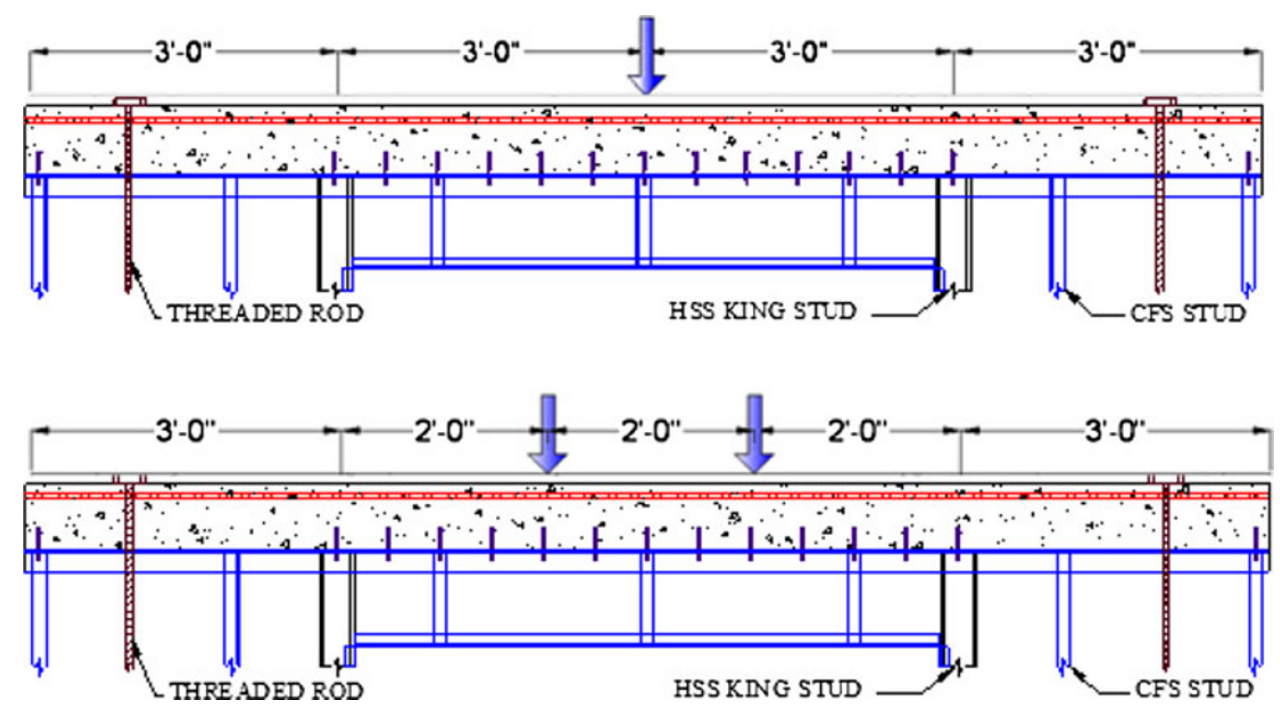

Fig. 12 Single- and two-point load tests for the header specimens. 


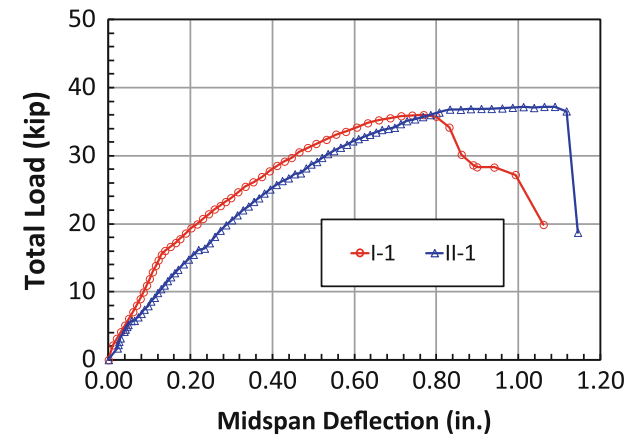

(a) Single-point loading

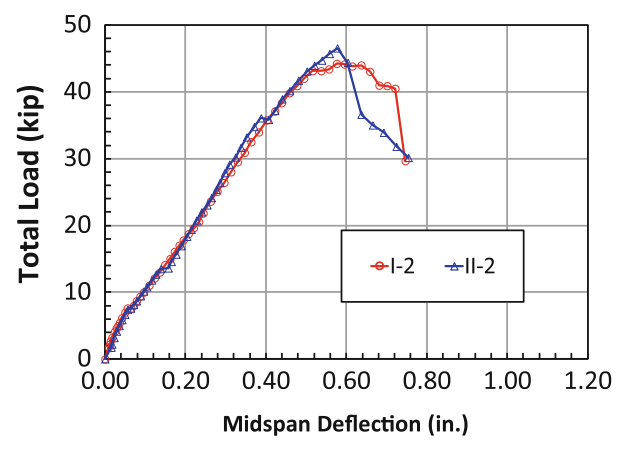

(b) Two-point loading

Fig. 13 Experimental load-deflection relationships for the header specimens.
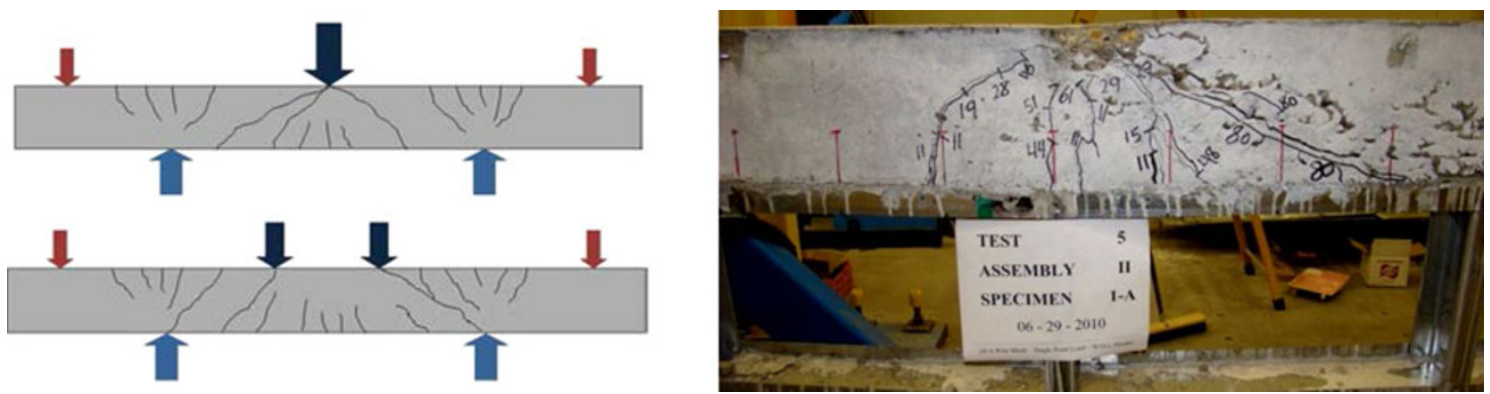

Fig. 14 Observed typical cracking patterns and flexural failure for the header specimens.
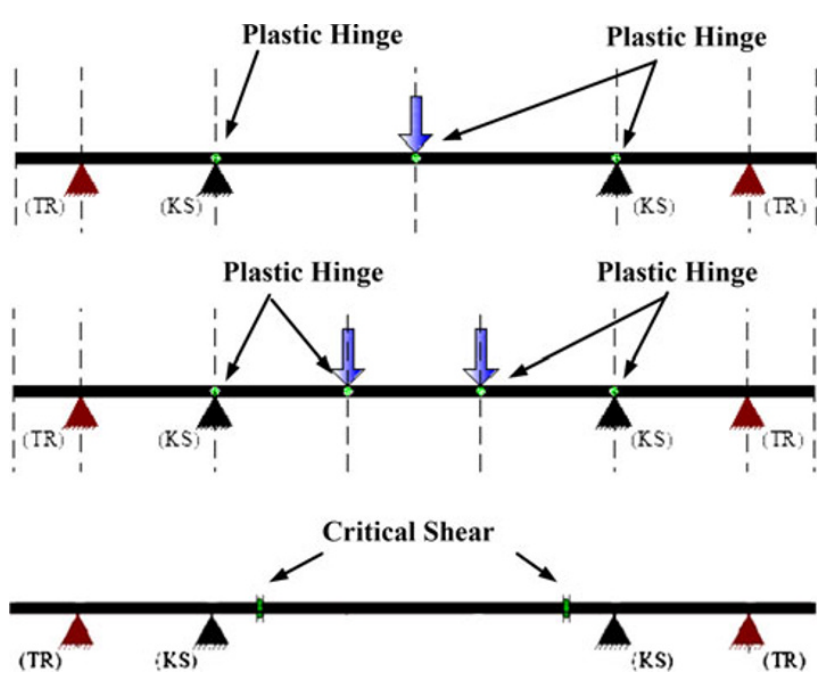

Fig. 15 Critical locations for plastic hinging and shear for the header specimens.

computer program XTRACT (Imbsen Software Systems 2000) was used to develop the moment-curvature relationships. The theoretical flexural capacities of the concrete/CFS beam in positive and negative bending were 32.8 and $15.4 \mathrm{k}$-ft., respectively. The total nominal shear strength of the concrete/CFS header was calculated by adding the nominal shear strengths of the concrete, wire-mesh, and CFS track. Fully composite action between the CFS track and concrete was assumed in computing the shear strength. The nominal shear strength of the concrete and the shear reinforcement were calculated according to the ACI code (American Concrete Institute 2011) provisions for shear, and the CFS shear strength was determined using the AISI (2007) and the AISC (2008) provisions. The effect of the variation in the wire mesh size on the overall shear strength was insignificant. The nominal shear capacity of the composite section was approximately 22 kips.

Flexural failure occurs when the compression concrete reaches the crushing strain (flexural strength limit state). When the flexural reinforcement amount is less than the maximum allowed by the code, flexural failure happens in a ductile manner and plastic rotation (hinging) will occur before failure. For the concrete/CFS beams considered in this study, the flexural reinforcement under both positive and negative bending was less the maximum amount allowed by the code. Since the concrete/CFS beam is redundant, the formation of a plastic hinge at one section along the beam will allow for moment redistribution. Therefore, the maximum load carrying capacity governed by flexure should be based on the load that induces a mechanism in the beam. If the shear strength at a section is reached prior to the formation of a mechanism, then the load carrying capacity will be governed by shear strength and the beam will fail in shear. Figure 15 shows locations of potential plastic hinging and critical shear. Table 3 presents comparisons between analytical and experimental strength evaluations. The results show very good agreement between the analytical and experimental results. Therefore, the behavior of concrete/CFS composite headers can be analyzed with good accuracy. Specimens under the two-point load achieved an average total load carrying capacity of 1.28 times that of the of the one-point load specimens. However, the two-point load specimens experienced significant shear cracking immediately after reaching their 
Table 3 Comparison of experimental and theoretical results for the header specimens.

\begin{tabular}{|c|c|c|c|c|c|c|}
\hline \multirow[t]{3}{*}{ Specimen } & \multirow{2}{*}{\multicolumn{2}{|c|}{$\begin{array}{c}\text { Theoretical \& numerical analysis } \\
\text { Total load (kip) }\end{array}$}} & \multirow{3}{*}{$\begin{array}{c}\begin{array}{c}\text { Experimental test } \\
\text { results }\end{array} \\
\text { Total load (kip) }\end{array}$} & \multirow{3}{*}{$\begin{array}{l}\text { Ratio of } \\
\text { experimental to } \\
\text { theoretical }\end{array}$} & \multicolumn{2}{|c|}{ Failure mode } \\
\hline & & & & & & \\
\hline & Based on flexure & Based on shear & & & Theoretical & Experimental \\
\hline $\mathrm{I}-1$ & 35.0 & 44.2 & 35.9 & 1.03 & Flexural & Flexural \\
\hline II-1 & 35.0 & 45.4 & 34.6 & 0.99 & Flexural & Flexural \\
\hline $\mathrm{I}-2$ & 42.0 & 45.0 & 44.2 & 1.05 & Flexural & Flexural \\
\hline II-2 & 43.0 & 43.6 & 46.2 & 1.07 & Flexural \& shear & Flexural \& shear \\
\hline
\end{tabular}

flexural capacity. The reduced shear span-to-depth ratio in the two-point load specimens as compared to the single point loading specimens required a higher load, and thus higher shear force, to develop the plastic hinges.

\section{Summary and Conclusions}

A series of experimental studies were performed on fullscale test specimens representing concrete/CFS beams and headers gravity loads. Continuity at the concrete-CFS interface was provided by $2 \frac{1}{2}$ in. $\times 5 / 16$ in. stand-off screws. The studies were designed to investigate the structural performance of concrete/CFS simple beams and concrete/CFS continuous headers.

Based on the results obtained from this study, the following conclusions are made.

1. Concrete/CFS composite beams can be designed for ductile flexural failure.

2. The use of stand-off screws as shear connectors is feasible for providing composite action. When adequate number and spacing of stand-off screws are furnished, the CFS track acts as tension reinforcement under positive bending and the concrete/CFS composite beams can attain their full flexural capacity.

3. When premature relative slip is prevented, the flexural response of concrete/CFS composite beams can be predicted with good accuracy.

4. The ACI expression for the effective moment of inertia may result in underestimation of $I_{e}$ at lower moments and overestimation of $I_{e}$ at higher moments.

5. The ACI provisions for flexural and shear strengths in beams can be applied to fully composite concrete/CFS beams.

6. The AISI equations for the bolt bearing capacity in bolted connections can be used for evaluating the bearing capacity of the stand-off screws in the CFS track.

7. Concrete/CFS composite headers are feasible to construct using stand-off screws to provide shear continuity at the interface. When adequate number and spacing of stand-off screws are used, concrete/CFS headers can achieve their full composite strength.

8. The structural behavior and strength of concrete/CFS composite headers can be modeled with good accuracy.

\section{Acknowledgments}

Funding for this study was provided by NUCOR Corporation in Norfolk, Nebraska. The findings and conclusions of this study are those of the authors and do not necessarily represent the opinion of NUCOR Corporation.

\section{Open Access}

This article is distributed under the terms of the Creative Commons Attribution License which permits any use distribution, and reproduction in any medium, provided the original author(s) and the source are credited.

\section{References}

American Concrete Institute. (2011). Building Code Requirements for Structural Concrete (ACI 318-08) and Commentary. Farmington Hills, MI.

American Institute of Steel Construction (AISC). (2008). Steel construction manual (13th Ed). Chicago, IL.

American Iron and Steel Institute (AISI). (2007). North American Specification for the Design of Cold-Formed Steel Structural Members. Washington, DC.

Bahmani, P. (2010). Structural performance of concrete/coldformed steel composite beams supporting composite floor decks. M.S. Thesis, South Dakota State University, Brookings, SD.

Imbsen Software Systems. (2000). XTRACT Version 2.6.2. Sacramento, CA.

International Code Council (ICC). (2012). International building code. Country Club Hills, IL.

Steel Stud Manufactures Association. (2012). Product technical guide. www.SSMA.com. Accessed on 29 Dec 2012.

Wehbe, A. P. (2009). Experimental evaluation of simple span cold-formed steel and concrete composite beams UTILIZING Shearflex ${ }^{\circledR}$ Connectors. M.S. Thesis. South Dakota State University, Brookings, SD. 